\title{
Clickable poly(2-oxazoline) architectures for the fabrication of low-fouling polymer capsules
}

\author{
Kristian Kempe, Sher Leen Ng, Ka Fung Noi, Markus Müllner, Sylvia T. Gunawan, Frank Caruso* \\ Department of Chemical and Biomolecular Engineering, The University of Melbourne, Victoria 3010, Australia \\ KEYWORDS polymer capsules, layer-by-layer, poly(2-oxazoline), fouling, click chemistry
}

\begin{abstract}
Hollow polymer capsules were prepared from linear as well as brush-like poly(2-oxazoline)s (POxs). Linear POxs containing alkene functionalities were obtained by cationic ring-opening polymerization (CROP), whereas the brush POxs bearing alkyne moieties were synthesized by a combination of CROP and reversible addition fragmentation chain transfer (RAFT) polymerization. Multilayers consisting of POx/poly(methacrylic acid) (PMA) were sequentially deposited onto silica particle templates and the films were stabilized either by thiol-ene (TE) chemistry or copper-catalyzed azidealkyne cycloaddition (CuAAc). Stable, monodisperse capsules were formed after removal of the silica particles with hydrofluoric acid, and were observed using fluorescence and atomic force microscopy (AFM). Both architectures exhibited lowfouling behavior, an essential criteria for therapeutic carriers to be utilized in bioapplications. In particular, the brush-like POx capsules show potential as a viable alternative material for the fabrication of low-fouling capsules.
\end{abstract}

The control of interactions between biological materials such as cells, proteins and bacteria, and synthetic carriers is of significant interest in drug delivery research. To permit the efficient delivery to the site of action, therapeutic carriers need to have a low level of nonspecific binding to biological materials, allowing for long circulation in blood. To avoid their recognition and clearance from the body, low-fouling and "stealth" behavior are of major importance for smart carrier systems. A polymer that is conventionally used to impart this property is poly(ethylene glycol) (PEG). ${ }^{1}$ However, several limitations associated with PEG, ${ }^{2}$ such as degradation by (auto)oxidation, hypersensitivity caused by the polymer as well as synthesis side products, high viscosity of concentrated solutions which leads to a poor bioavailability, and non-biodegradability have led to recent research on the development of new alternative materials. ${ }^{3,4}$ Among them, poly(2-oxazoline)s (POx) have emerged as interesting candidates, ${ }^{5}$ which combine excellent biocompatibility, ${ }^{5,6}$ stealth behavior and protein repellence,, 8 with the ease of synthesizing highly functional systems. ${ }^{9-11}$ To date, POx-based particulate systems have been obtained by self-assembly of amphiphilic block copolymers, nanoprecipitation ${ }^{12}$ or by surface modification of existing particles. ${ }^{13}$ However, in recent years, a highly versatile technique for the fabrication of multilayer thin films and nanoscale engineered assembly of materials, known as the layer-by-layer (LbL) technique,14-16 has gained significant interest. Recently, hydrogen-bonded LbL assembly has been used to prepare POx/tannic acid multilayers. ${ }^{17,18}$ The LbL technique has also been exploited for the fabrication of functional drug carriers ${ }^{19}$ with crucial properties that include "stealth" behavior, targeting groups and release mechanisms. ${ }^{20}$ Typically, "stealth" is achieved by decorating the capsule corona with PEG moieties and layers, respectively. Furthermore, LbL has previ- ously been used to prepare single-component crosslinked PEG $^{21}$ and poly(vinylpyrrolidone) (PVPON) ${ }^{22,23}$ films and capsules, which exhibit low-fouling properties. These systems have recently been used for specific targeting of cancer cells. ${ }^{24-26}$ Despite these studies, there still exists a need for exploring simple and modular chemistries to assemble low-fouling materials with readily tunable properties. The modularity of POx allows for the straightforward incorporation of side and end group functionalities. ${ }^{11,27}$ Finetuning of the material properties is achieved by copolymerization with different substituted 2-oxazolines ${ }^{28}$ and, as recently reported, by the combination with other living/controlled polymerization techniques. ${ }^{29-31}$ This versatility provides access to a vast variety of polymer architectures, such as linear, brush and star-shaped polymers with readily tunable properties. Herein, we report the utilization of linear as well as brush-like POx for the fabrication of multilayer films on both planar and particle supports. Film stabilization was achieved using two different efficient coupling reactions; copper-catalyzed azide-alkyne cycloaddition (CuAAc) and thiol-ene (TE) chemistry, respectively. The influence of the POx architecture on the protein fouling behavior of the respective capsules was investigated.

Two different POx architectures, namely linear and brush-like POx, which bear functionalities that are suitable to undergo efficient postpolymerization modification reactions, were prepared. Functional poly(2-ethyl-2-oxazoline) (PEtOx)-based copolymers were obtained by copolymerization with alkene and alkyne-containing comonomers that are able to react in $\mathrm{TE}$ and $\mathrm{CuAAc}$ reactions, respectively. The linear POx, referred to as L-PEtOxTE, was obtained by CROP of EtOx and 2-dec-(9-enyl)-2-oxazoline (DecEnOx; Scheme 1A), a comonomer employed for func- 
tionalization and crosslinking via TE reactions. ${ }^{27}$ To pre-

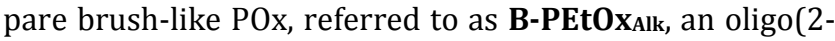
ethyl-2-oxazoline)methacrylate (OEtOxMA) macromonomer $^{32}$ was copolymerized with a trimethylsilyl (TMS)protected alkyne monomer by reversible addition fragmentation chain transfer (RAFT) polymerization (Scheme 1B).

Scheme 1. Schematic representation of the synthesis of linear

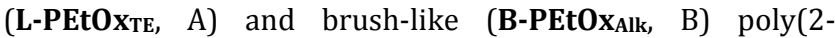
oxazoline)s (POxs).

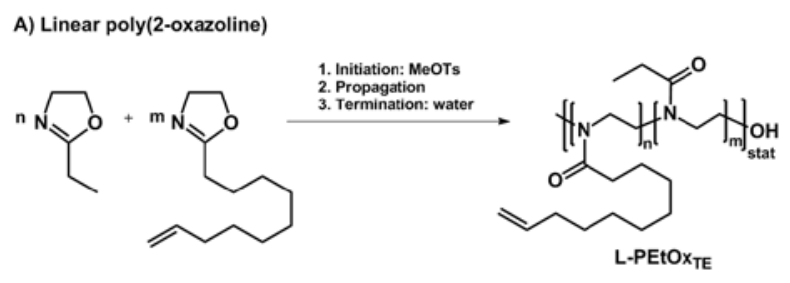

B) Brush-like poly(2-oxazoline)

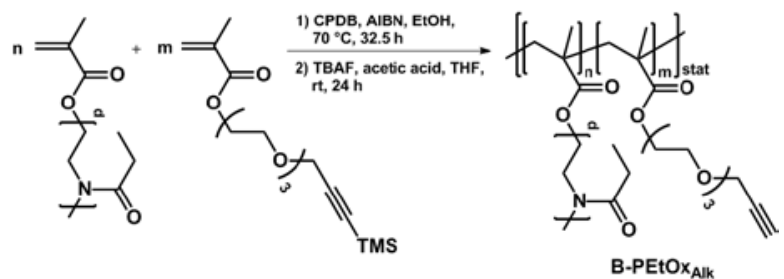

This study, to our knowledge, represents the first report of a POx brush with clickable moieties in the side chain obtained by RAFT. The amount of clickable monomer units was determined by ${ }^{1} \mathrm{H}$ NMR to be $7 \%$ and $14 \%$ for $\mathbf{L}-$

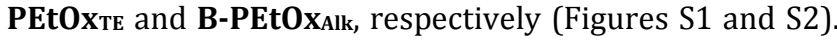
It is noteworthy that the latter system required a higher percentage of functional groups to efficiently stabilize the capsule walls. B-PEtOx $\mathbf{x}_{\text {Alk }}$ with $8 \%$ functionalization resulted in the formation of ill-defined capsules (data not shown). SEC measurements revealed the synthesis of welldefined copolymers with polydispersity index (PDI) values $<1.3$. For a summary of the characterization data refer to Table S1.

The assembly of POx and PMA multilayer films via hydrogen bonding was monitored on planar supports using a quartz crystal microbalance (QCM). To investigate the influence of $\mathrm{pH}$ on the film assembly, the buffer $\mathrm{pH}$ was adjusted to 2.5, 4 and 5. L-PEtOx $\mathbf{x}_{\mathrm{TE}}$ (Figure 1A) and BPEtOx $_{\text {Alk }}$ (Figure 1B) showed the same trend for film buildup, where the frequency decreased with the number of layers deposited. Thus, the polymers examined were able to undergo hydrogen bonding and form multilayer films at all pH values used $(2.5,4$, and 5). As reported for PEtOx/PMA systems, hydrogen bonding is observed up to $\mathrm{pH} 5 .^{33}$ The copolymers used in this study showed a similar behavior. Multilayer buildup at pH 5 differed from buildup at lower $\mathrm{pH}$ values, where significantly lower frequency changes were observed. The changes in QCM frequency of the films from one to the consecutive bilayer were in a similar range for $\mathrm{pH} 2.5$ and 4 (40-50 Hz per bilayer). These values are similar to other hydrogen bonded systems such as PMA/PVPON, ${ }^{34}$ suggesting the formation of thin POx/PMA films. However, due to the higher protonation of the PMA at low $\mathrm{pH}$, hydrogen bond interactions are more pronounced, resulting in a slightly larger frequency change per deposited layer.

The results obtained from the planar support studies were applied for the buildup of films on particle templates. The formation of POx/PMA multilayers was examined on monodisperse $\mathrm{SiO}_{2}$ particles (2.59 $\mu \mathrm{m}$ in diameter) at $\mathrm{pH}$ 2.5 and 4 (20 mM NaOAc). To quantify the buildup, PMA was prelabeled with AF488-cadavarine and the particle fluorescence was measured by flow cytometry after deposition of each bilayer. Linear and regular buildup was observed in each case, independent of the architecture of the POx (Figure 1C, D). However, the difference in the deposition at pH 2.5 and 4 was more pronounced for B-PEtOx $\mathbf{x}_{\text {Alk. }}$ These results are in agreement with the QCM data for the buildup on planar substrates. However, the film buildup is different to that observed for brush-like PEG, which showed an exponential trend. ${ }^{21}$ This PEG growth behavior was attributed to polymer migration within the multilayers during the assembly. We note that polymer capsules based on linear PEG have not yet been reported.

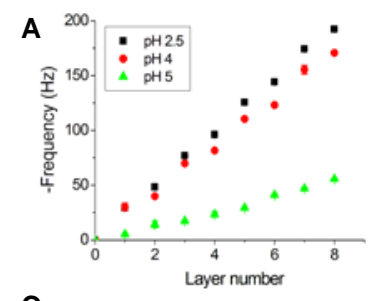

C

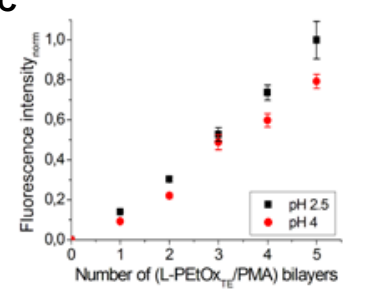

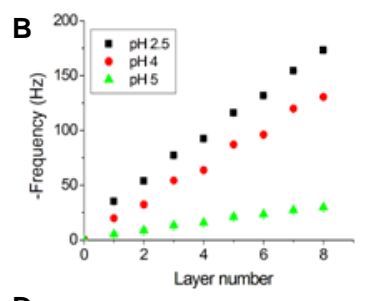

D

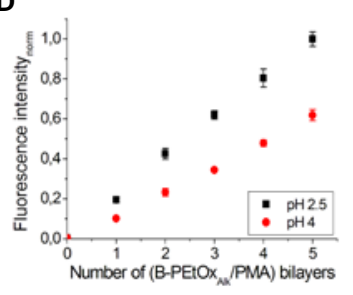

Figure 1. LbL assembly of L-PEtOx $\mathbf{x}_{\mathrm{TE}} / \mathrm{PMA}$ (left) and BPEtOx $_{\text {Alk }} / \mathrm{PMA}$ (right) bilayers $\left(23{ }^{\circ} \mathrm{C}, 20 \mathrm{mM} \mathrm{NaOAc}\right)$ at different $\mathrm{pH}$. (A, B) Film assembly on planar supports, as monitored by QCM. Layer 0 corresponds to the PMA layer deposited via electrostatic interactions onto a PEI-coated surface. Odd and even numbers correspond to POx and PMA layers. (C, D) Film assembly on particle supports $\left(\mathrm{SiO}_{2}, 2.59 \mu \mathrm{m}\right)$, as monitored by flow cytometry. PMA was prelabeled with AF488-cadavarine. Measurements were taken after each PMA layer was deposited.

To study the crosslinking conditions for the preparation of stable hollow POx capsules (i.e., capsules that retain their structural integrity at $37^{\circ} \mathrm{C}$ and $\mathrm{pH}$ 7.4), five bilayers of L-PEtOX $\mathbf{x}_{\text {TE }}$ or B-PEtOx $\mathbf{x}_{\text {Alk }}$ and PMA were deposited onto silica particle templates. In addition, two nonfunctionalized sacrificial PVPON/PMA bilayers were added as capping layers to minimize interparticle crosslinking (Scheme 2). From the studies on both the planar and particle supports, we chose to conduct the multilayer assembly at $\mathrm{pH} 4$, as this $\mathrm{pH}$ ensures sufficient film buildup.

Scheme 2. Preparation of "click"-stabilized POx capsules via hydrogen-bonded LbL assembly of POx and PMA. 


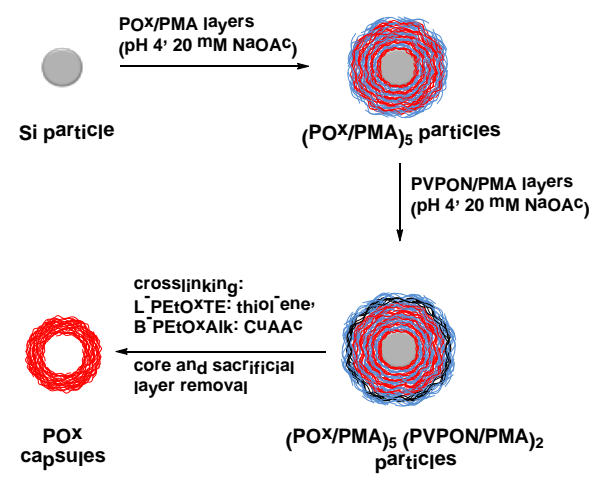

The crosslinking of B-PEtOxalk layers, to yield the respective capsules (Figure 2B), was performed in a similar manner as with other reported CuAAc "click" capsules,35 whereas the TE crosslinking, presented here, required establishing appropriate conditions for stabilization of the L-PEtOX $\mathbf{x}_{\mathrm{TE}}$-based systems. The efficient crosslinking of multilayers exploiting polar TE reactions, referred to as Michael-addition, has been previously reported. ${ }^{36}$ In contrast, non-activated alkene groups, such as the terminal double bond present in the DecEnOx monomer are susceptible to radical TE reactions. ${ }^{37,38}$ More recently, functional hydrogels were prepared from DecEnOx and difunctional thiols. ${ }^{39}$ In general, the radical TE reaction can be initiated either by UV irradiation or thermal heating. ${ }^{40}$ Here, watersoluble UV as well as thermal radical initiators and two different dithiols, namely dithiothreitol (DTT) and 2', 2'(ethylenedioxy)-diethanethiol (EDDT) were tested for crosslinking of the multilayer films. UV-initiated thiol-ene reactions were not successful. It was assumed that at the $\mathrm{pH}$ conditions chosen the initiator became inactive. In contrast, thermal crosslinking yielded stable capsule systems after removal of the particle template and the sacrificial PMA by washing the capsules into PBS (Figure 2A, C). However, it was observed that the crosslinker influenced the capsule stability. Using a shorter crosslinker (DTT), the multilayers could be readily stabilized, whereas the longer crosslinker (EDDT) yielded only a marginal number of capsules, which appeared less robust. This observation might be attributed to denser crosslinking using the shorter crosslinker. L-PEtOx $\mathbf{x}_{\mathrm{TE}}$, with a rather low molar mass $(5$ $\mathrm{kDa}$ ), yielded stable capsules as observed under the fluorescence microscope (Figure 2A). In addition, the capsules were analyzed using AFM. Analysis of the air-dried POx capsules revealed spherical structures with folds and creases typical for polymer capsules prepared by the LbL technique (Figure 2C, D).
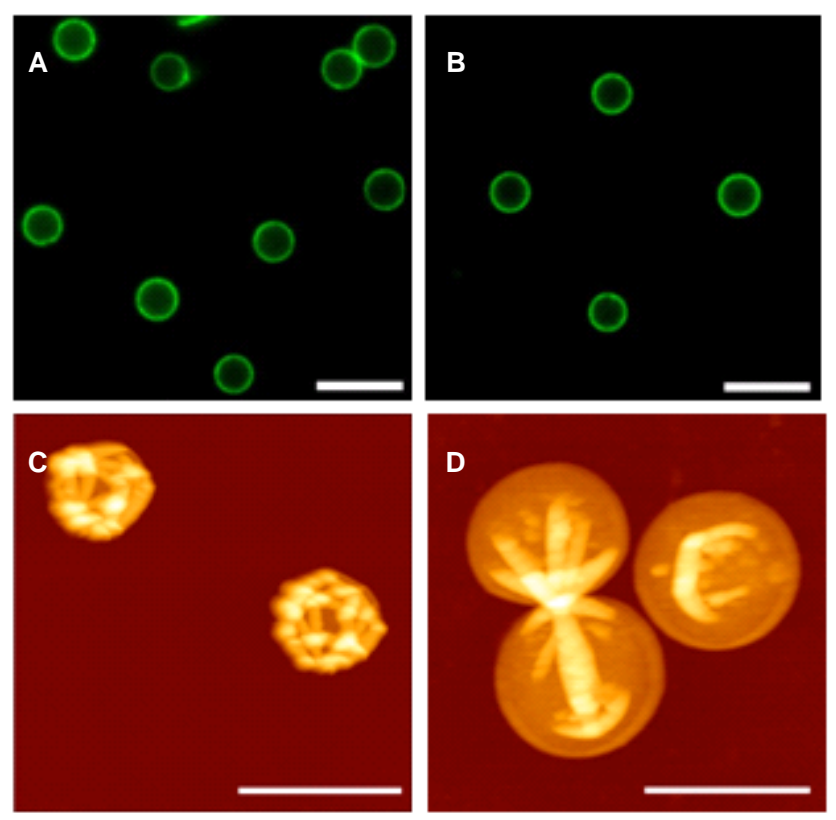

Figure 2. Fluorescence microscopy (top) and atomic force microscopy (bottom) images of L-PEtOxTE (A, C) and BPEtOX $_{\text {Alk }}$ (B, D) capsules assembled on a sacrificial core of 2.78 $\mu$ m diameter $\mathrm{SiO}_{2}$ particles at $\mathrm{pH} 4(\mathrm{NaOAc}, 20 \mathrm{mM})$. Scale bars $=5 \mu \mathrm{m}$.

Extended blood circulation times are crucial for systems applied in biology since it increases the bioavailability for delivery to the site of action. As human serum contains numerous different proteins, the ability of the POx capsules to resist protein adsorption was investigated using two representative proteins, namely bovine serum albumin (BSA) and lysozyme. In particular, the influence of the architecture of the POx systems used, linear (L-PEtOX $\mathbf{x E}_{\mathrm{TE}}$ and brush-like (B-PEtOx $\mathbf{x}_{\text {Alk }}$ ), on the fouling behavior was considered for this study. The capsules were incubated with FITC-labeled proteins at $37^{\circ} \mathrm{C}$ for $1 \mathrm{~h}$. After incubation, the capsules were washed with PBS and the relative amount of adsorbed proteins on the particles was determined using flow cytometry. As a comparison, PVPON capsules stabilized by CuAAc were synthesized and treated in the same way as PVPON capsules have been reported to exhibit low fouling behavior compared to higher fouling systems such as PSS, PAH and PDPA.22 These highly charged systems show protein adsorption of about 6 times higher than PVPON, highlighting the low-fouling character of the PVPON system. The fouling experiments revealed that POx capsules were similarly capable of resisting proteins as PVPON (Figure 3). Specifically, B-PEtOxalk capsules showed an improvement in fouling behavior, with $\sim 40 \%$ lower associated protein than the L-PEtOx $\mathbf{x}_{\mathrm{TE}}$ capsules, in both protein solutions.

It is known that a low-fouling system typically requires a well-hydrated polymer to be capable of repelling proteins. ${ }^{41}$ The statistical distribution of the alkene groups within the L-PEt0 $\mathbf{x}_{\mathrm{TE}}$ copolymer ${ }^{12}$ causes a relatively flat arrangement of the POx chains on the surface after crosslinking, preventing the exposure of entangled chains from the surface, limiting effective hydration. This is supported by the low swelling of hydrogels prepared from $\mathrm{P}(\mathrm{EtOx}-\mathrm{Co}$ DecEnOx) systems. ${ }^{39}$ Furthermore, the hydrophobicity of 
DecEnOx units and free thiol groups might increase the interactions of the capsules with proteins. In contrast, the B-PEtOx $x_{\text {Alk }}$ capsules display PEtOx brushes, which might be better hydrated, thus having potentially increased protein resistance properties. ${ }^{41}$ However, even though BPEtOxalk contains only a minor amount of comonomer, we cannot rule out some influence of the OPEG chains.
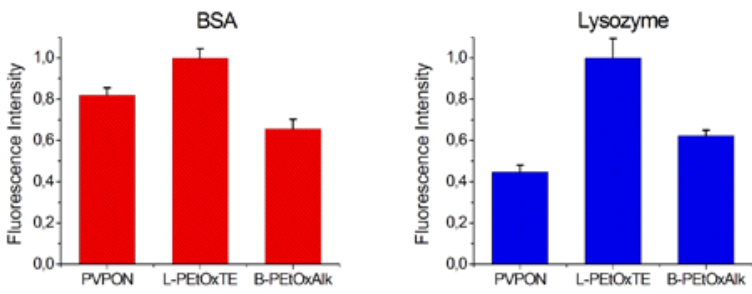

Figure 3. Flow cytometry analysis of the fouling behavior of PVPON, L-PEtOxTE and B-PEtOx $x_{\text {Alk }}$ capsules with FITC-BSA (left) and FITC-lysozyme (right). Unlabeled capsules were incubated with $1 \mathrm{mg} \mathrm{mL}^{-1}$ protein (BSA or lysozyme) in $\mathrm{pH} 7.4$ PBS for $1 \mathrm{~h}$, before being measured for protein association on the capsule surfaces. Each measurement was performed in triplicate. Error bars show the average deviation from the mean.

In conclusion, the fabrication of POx-based polymer capsules is reported. To this end, two different polymers with linear and brush-like architecture were prepared. Their deposition on planar as well as particle supports revealed a regular and linear film buildup at $\mathrm{pH} 2.5$ and 4 . CuAAc and TE chemistries were employed for the crosslinking of the films, yielding in both cases stable thin-film polymer capsules. Both POx architectures rendered the corresponding capsules low-fouling, with brush-like POx capsules showing lower protein adsorption. The interaction of $\mathrm{POx}$ capsules with biological material and their response to external stimuli for triggered release of cargo is currently under investigation in our laboratory.

\section{ASSOCIATED CONTENT}

Supporting Information. Experimental data and supporting spectra. This material is available free of charge via the Internet at http://pubs.acs.org.

\section{AUTHOR INFORMATION}

\section{Corresponding Author}

*E-mail: fcaruso@unimelb.edu.au

\section{Author Contributions}

The manuscript was written through contributions of all authors.

\section{ACKNOWLEDGMENT}

$\mathrm{K}$. Kempe is grateful to the Alexander von Humboldtfoundation for a Feodor-Lynen fellowship. M. Müllner thanks The University of Melbourne for a McKenzie Fellowship. F. Caruso acknowledges funding from the Australian Research Council under the Australian Laureate Fellowship scheme (FL1201100030).

\section{REFERENCES}

1. Pasut, G.; Veronese, F. M. J. Control. Release 2012, 161, 461-472.
2. Knop, K.; Hoogenboom, R.; Fischer, D.; Schubert, U. S. Angew. Chem. Int. Ed. 2010, 49, 6288-6308.

3. Schlapschy, M.; Binder, U.; Borger, C.; Theobald, I.; Wachinger, K.; Kisling, S.; Haller, D.; Skerra, A. Protein Eng. Des. Sel. 2013, 26, 489-501.

4. Mero, A.; Pasut, G.; Via, L. D.; Fijten, M. W. M.; Schubert, U. S.; Hoogenboom, R.; Veronese, F. M. J. Control. Release 2008, 125, 87 95.

5. Luxenhofer, R.; Han, Y. C.; Schulz, A.; Tong, J.; He, Z. J.; Kabanov, A. V.; Jordan, R. Macromol. Rapid Commun. 2012, 33, 1613-1631.

6. Sedlacek, O.; Monnery, B. D.; Filippov, S. K.; Hoogenboom, R.; Hruby, M. Macromol. Rapid Commun. 2012, 33, 1648-1662.

7. Tauhardt, L.; Kempe, K.; Gottschaldt, M.; Schubert, U. S. Chem. Soc Rev. 2013, 42, 7998-8011.

8. Konradi, R.; Acikgoz, C.; Textor, M. Macromol. Rapid Commun. 2012 33, 1663-1676.

9. Hoogenboom, R. Angew. Chem. Int. Ed. 2009, 48, 7978-7994.

10. Makino, A.; Kobayashi, S. J. Polym. Sci., Part A: Polym. Chem. 2010 $48,1251-1270$

11. Guillerm, B.; Monge, S.; Lapinte, V.; Robin, J. J. Macromol. Rapid Commun. 2012, 33, 1600-1612.

12. Kempe, K.; Vollrath, A.; Schaefer, H. W.; Poehlmann, T. G.; Biskup, C.; Hoogenboom, R.; Hornig, S.; Schubert, U. S. Macromol. Rapid Commun. 2010, 31, 1869-1873.

13. Manzenrieder, F.; Luxenhofer, R.; Retzlaff, M.; Jordan, R.; Finn, M. G. Angew. Chem. Int. Ed. 2011, 50, 2601-2605.

14. Decher, G. Science 1997, 277, 1232-1237.

15. Caruso, F.; Caruso, R. A.; Möhwald, H. Science 1998, 282, 11111114.

16. Such, G. K.; Johnston, A. P. R.; Caruso, F. Chem. Soc. Rev. 2011, 40, 19-29.

17. Erel, I.; Schlaad, H.; Demirel, A. L. J. Colloid Interface Sci. 2011, 361 , 477-482.

18. Antunes, A. B. D. F.; Dierendonck, M.; Vancoillie, G.; Remon, J. P.; Hoogenboom, R.; De Geest, B. G. Chem. Commun. 2013, 49, $9663-$ 9665.

19. Becker, A. L.; Johnston, A. P. R.; Caruso, F. Small 2010, 6, 18361852.

20. De Koker, S.; Hoogenboom, R.; De Geest, B. G. Chem. Soc. Rev. 2012, 41, 2867-2884.

21. Leung, M. K. M.; Such, G. K.; Johnston, A. P. R.; Biswas, D. P.; Zhu, Z. Y.; Yan, Y.; Lutz, J. F.; Caruso, F. Small 2011, 7, 1075-1085.

22. Kinnane, C. R.; Such, G. K.; Antequera-Garcia, G.; Yan, Y.; Dodds, S. J.; Liz-Marzan, L. M.; Caruso, F. Biomacromolecules 2009, 10, 2839-2846

23. Ng, S. L.; Such, G. K.; Johnston, A. P. R.; Antequera-Garcia, G.; Caruso, F. Biomaterials 2011, 32, 6277-6284.

24. Kamphuis, M. M. J.; Johnston, A. P. R.; Such, G. K.; Dam, H. H.; Evans, R. A.; Scott, A. M.; Nice, E. C.; Heath, J. K.; Caruso, F. J. Am. Chem. Soc. 2010, 132, 15881-15883.

25. Johnston, A. P. R.; Kamphuis, M. M. J.; Such, G. K.; Scott, A. M.; Nice, E. C.; Heath, J. K.; Caruso, F. ACS Nano 2012, 6, 6667-6674.

26. Leung, M. K. M.; Hagemeyer, C. E.; Johnston, A. P. R.; Gonzales, C.; Kamphuis, M. M. J.; Ardipradja, K.; Such, G. K.; Peter, K.; Caruso, F. Angew. Chem. Int. Ed. 2012, 51, 7132-7136.

27. Kempe, K.; Hoogenboom, R.; Jaeger, M.; Schubert, U. S Macromolecules 2011, 44, 6424-6432.

28. Kempe, K.; Lobert, M.; Hoogenboom, R.; Schubert, U. S. J. Polym Sci., Part A: Polym. Chem. 2009, 47, 3829-3838.

29. Weber, C.; Becer, C. R.; Guenther, W.; Hoogenboom, R.; Schubert, U. S. Macromolecules 2010, 43, 160-167.

30. Krieg, A.; Weber, C.; Hoogenboom, R.; Becer, C. R.; Schubert, U. S. ACS Macro Lett. 2012, 1, 776-779.

31. Marx, L.; Volet, G.; Amiel, C. J. Polym. Sci., Part A: Polym. Chem. 2011, 49, 4785-4793.

32. Weber, C.; Becer, C. R.; Hoogenboom, R.; Schubert, U. S. Macromolecules 2009, 42, 2965-2971.

33. Kwon, I. C.; Bae, Y. H.; Kim, S. W. Nature 1991, 354, 291-293.

34. Zelikin, A. N.; Quinn, J. F.; Caruso, F. Biomacromolecules 2006, 7 27-30.

35. Liang, K.; Such, G. K.; Zhu, Z. Y.; Yan, Y.; Lomas, H.; Caruso, F. Adv Mater. 2011, 23, H273-H277.

36. Connal, L. A.; Kinnane, C. R.; Zelikin, A. N.; Caruso, F. Chem. Mater 2009, 21, 576-578. 
37. Kade, M. J.; Burke, D. J.; Hawker, C. J. J. Polym. Sci., Part A: Polym. Chem. 2010, 48, 743-750.

38. Hoyle, C. E.; Bowman, C. N. Angew. Chem. Int. Ed. 2010, 49, 15401573.

39. Dargaville, T. R.; Forster, R.; Farrugia, B. L.; Kempe, K.; Voorhaar, L.; Schubert, U. S.; Hoogenboom, R. Macromol. Rapid Commun. 2012, 33, 1695-1700.
40. Campos, L. M.; Killops, K. L.; Sakai, R.; Paulusse, J. M. J.; Damiron, D.; Drockenmuller, E.; Messmore, B. W.; Hawker, C. J. Macromolecules 2008, 41, 7063-7070.

41. Chen, S. F.; Li, L. Y.; Zhao, C.; Zheng, J. Polymer 2010, 51, 52835293. 
Table of Contents

Clickable poly(2-oxazoline) architectures for the fabrication of low-fouling polymer capsules

Kristian Kempe, Sher Leen Ng, Ka Fung Noi, Markus Müllner, Sylvia T. Gunawan, Frank Caruso*

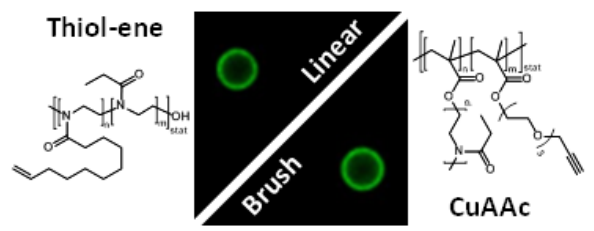




\section{University Library}

\section{- M M N E R VA A gateway to Melbourne's research publications}

Minerva Access is the Institutional Repository of The University of Melbourne

Author/s:

Kempe, K;Ng, SL;Noi, KF;Muellner, M;Gunawan, ST;Caruso, F

Title:

Clickable Poly(2-oxazoline) Architectures for the Fabrication of Low-Fouling Polymer Capsules

Date:

2013-12-01

Citation:

Kempe, K., Ng, S. L., Noi, K. F., Muellner, M., Gunawan, S. T. \& Caruso, F. (2013). Clickable Poly(2-oxazoline) Architectures for the Fabrication of Low-Fouling Polymer Capsules. ACS MACRO LETTERS, 2 (12), pp.1069-1072. https://doi.org/10.1021/mz400522e.

Persistent Link:

http://hdl.handle.net/11343/123293 